\title{
'They are inconveniencing us' - exploring how gaps in patient education and patient centred approaches interfere with TB treatment adherence: perspectives from patients and clinicians in the Free State Province, South Africa
}

\author{
N. Moodley ${ }^{1,2^{*}}$, A. Saimen ${ }^{1}$, N. Zakhura ${ }^{3}$, D. Motau ${ }^{3}$, G. Setswe' ${ }^{1}$ S. Charalambous ${ }^{1,4}$ and C. M. Chetty-Makkan ${ }^{1}$
}

\begin{abstract}
Background: Tuberculosis (TB) treatment loss to follow up (LTFU) plays an important contributory role to the staggering TB epidemic in South Africa. Reasons for treatment interruption are poorly understood. Treatment interruption appears to be the culmination of poor health literacy of patients and inadequate health education provided by clinicians. We explored clinician and patient perspectives of the gaps in TB messaging that influence TB treatment LTFU.

Methods: We conducted semi-structured in-depth interviews between January and May 2018 with a sample of 15 clinicians managing TB and 7 patients identified as LTFU in public clinics in the Free State Province, South Africa. Thematic analysis using a mixed deductive/inductive thematic approach was used.

Results: Limited occupational opportunities, fear of disclosure and stigmatization all contributed to treatment LTFU. Patients felt that the TB messaging received was inadequate. Many of the clinicians interviewed felt that improving patient's TB knowledge would reinforce adherence to treatment and thus focused on sharing information on treatment completion, side effects and infection control. However, the inability of clinicians to establish rapport with patients or to identify social support challenged TB treatment adherence by patients. Clinicians perceived this as patients not following their instructions despite what they considered lengthy TB education. Having said this, clinicians concurred that their medical management of TB lacked the psycho-social dimension to treat a social disease of this magnitude.

\footnotetext{
* Correspondence: nishila.moodley@jcu.edu.au

${ }^{1}$ The Aurum Institute, Johannesburg, South Africa

${ }^{2}$ College of Medicine and Dentistry, James Cook University, 1 James Cook

Drive, Douglas, Townsville, Queensland 4814, Australia

Full list of author information is available at the end of the article
}

(c) The Author(s). 2020 Open Access This article is licensed under a Creative Commons Attribution 4.0 International License, which permits use, sharing, adaptation, distribution and reproduction in any medium or format, as long as you give appropriate credit to the original author(s) and the source, provide a link to the Creative Commons licence, and indicate if changes were made. The images or other third party material in this article are included in the article's Creative Commons licence, unless indicated otherwise in a credit line to the material. If material is not included in the article's Creative Commons licence and your intended use is not permitted by statutory regulation or exceeds the permitted use, you will need to obtain permission directly from the copyright holder. To view a copy of this licence, visit http://creativecommons.org/licenses/by/4.0/. The Creative Commons Public Domain Dedication waiver (http://creativecommons.org/publicdomain/zero/1.0/) applies to the data made available in this article, unless otherwise stated in a credit line to the data. 
(Continued from previous page)

Conclusions: Limited occupational opportunities, fear of disclosure and stigmatization all contributed to treatment

LTFU. Clinicians concurred that poor patient understanding of TB and that biomedical management lacking a psycho-social dimension further exacerbated the poor treatment outcome. TB remains a social disease, the successful management of which hinges on patient-centred care.

Keywords: Tuberculosis TB, Adherence, Messaging, Loss to follow up, Knowledge, Health literacy, Patient-centered care

\section{Background}

Tuberculosis (TB) remains the leading cause of death from a single infectious agent globally, ranking higher than HIV/AIDS (human immunodeficiency virus/ acquired immunodeficiency syndrome), and despite treatment being available [1]. In 2018, South Africa ranked fourth on the list of high TB burden countries based on absolute number of TB cases with an estimated 520 incident cases per 100,000 population [1]. The fragmented South African health system is largely accountable for the diagnostic delays, inconsistent guideline implementation and poor TB outcomes that mar the TB programme [2]. The comprehensive cascade of care analysis conducted by Naidoo et al on the 2013 programmatic data revealed that $5 \%$ were unable able to access $\mathrm{TB}$ testing, $13 \%$ did not receive their TB diagnosis and 12\% were never initiated on treatment [3]. However, evidence suggests that these 'missed' cases continue to engage with the health system and the system fails to manage them appropriately [3]. In 2016, South African data estimates that $17 \%$ of patients initiating $\mathrm{TB}$ treatment failed to complete their treatment; an attrition equivalent to 92, 761 individuals [3].

TB control efforts are persistently undermined by social, financial and clinical barriers to care [4]. TB treatment adherence is vital in achieving disease cure in individual patients and preventing disease spread within the community [5]. The World Health Organization's (WHO) has declared the ongoing emergence and spread of drug resistant $\mathrm{TB}$ a global crisis, emphasizing the necessity for $\mathrm{TB}$ patients to complete their course of $\mathrm{TB}$ treatment [1]. Patients incur considerable out of pocket expenses in accessing TB services despite TB diagnosis and care services being offered free in South Africa; with the poorest patients incurring highest relative costs [6]. Poor treatment adherence increases the length and severity of illness and complicates disease transmission and drug resistance; carrying negative economic consequences for the patient, community and the health system [7].

Studies exploring TB treatment completion generally adopt a bio-medical approach, though TB has long been considered a 'social' disease [8]. Socioeconomic and individual circumstances including patients' sense of feeling better, occupational commitments, side effects, and misinformation on treatment duration impact heavily on treatment completion [9-14]. Health education is integrated into services provided at primary health care (PHC) level in South Africa [15]. However, inadequate patient counselling on treatment expectations $[16,17]$ and inconsistent implementation of the Directly Observed Treatment, Short Course (DOTS) strategy [18, 19] continue to exacerbate TB treatment LTFU. Apart from South Africa, similar findings of poor patientprovider communication hindering TB treatment completion have been demonstrated as far afield as Eritrea, Tanzania, Pakistan and Ethiopia; always with the discussion prioritizing strengthened patient-provider trust and treatment literacy [20-24].

The WHO End TB Strategy has endorsed a holistic patient centred model of care, focused on patient rights and welfare, to improve TB outcomes globally [25-27]. Disseminating accurate, evidence-based TB information among patients and clinicians alike, is fundamental to achieving this. Data from as far back as 1997 purported that TB care in South Africa remained nurse-centred with poor receptivity and confirmation by the patient [28].

Despite the need to empower patients to actively manage their TB, current literature lacks feasible approaches to accomplish this empowerment. This study allows for exploration of the complex social, cultural and environmental phenomena relating to TB treatment LTFU in the Free State Province and identifies potential areas for improvement.

\section{Methods \\ Setting}

This study was conducted at three public health facilities in the Mangaung District (Free State Province, South Africa) that served high density, marginalised communities with rife unemployment and poverty [29]. HIV prevalence and TB mortality were estimated at 11 and 9\% respectively in the in the district [29]. The incidence of drug sensitive TB among those commenced on TB treatment in the Free State Province (2017) was 429.8 per 100,000 , compared with the national average of 378.6 per 100,000 [30]. Tuberculosis was the leading cause of 
death, irrespective of age or sex, in the Free State Province [31] and HIV-positive TB mortality accounted for $73 \%$ of deaths among patients with TB in 2018 [1]. Further, $94 \%$ of patients newly diagnosed with TB were initiated on TB treatment and $90 \%$ of those patients who were TB/HIV co-infected were able to access antiretroviral therapy [29]. Patients documented as LTFU regarding their TB treatment and clinicians that managed patients with TB at these facilities were approached to participate in the study.

\section{Design}

This exploratory qualitative study was conducted between January and May 2018 with purposive sampling used to select patients. Three research assistants (RAs) that conducted the in-depth interviews (IDIs) were Good Clinical Practice (GCP) accredited, trained in qualitative data collection, had previous interviewing experience and fluent in the local languages (English, Sesotho, and Setswana). During training, interviewers were assessed and given feedback following direct observations on their ability to collect data using the interview guides. The investigators regularly reviewed the interviews and provided frequent feedback to the research assistants. Debriefing sessions were arranged to discuss experiences of conducting interviews, interview content, how to improve probing skills and address challenges.

The interviewers prior contact with the patients was limited to arranging interviews. The interviewers had engaged with the clinicians previously during quantitative TB work conducted at the facilities. Participants were provided with information on the qualitative component of the study and the interviewer's role during the interview. The semi-structured interview questions allowed for the successive coding process required for deductive/ inductive thematic analysis approach.

\section{Data collection}

Patients and clinicians that were willing to provide written voluntary informed consent and agreed for the session to be digitally recorded were interviewed. Separate interview guides were developed for the patients (Annexure 1) and clinicians (Annexure 2) that explored access to health care, perceived quality of care, TB knowledge and how treatment support impacted TB treatment completion. The interviews were audiorecorded and were between 30 to $90 \mathrm{~min}$. Basic demographic information (e.g. age, level of education, distance to clinic, and source of income, history of comorbidities) was collected from patients (Annexure 3: Table 1). Information on position of employment and years of experience was collected from clinicians (Annexure 3: Table 2). The interviewers made field notes after the interviews. It was the author's assessment that saturation was reached by revising the probes during data collection.

Patients listed on electronic TB records from study facilities; aged $\geq 18$ years and documented as LTFU (as per the WHO treatment outcome definition [32]), were invited to participate in the study. The sample varied by age and gender. Patient contact information was retrieved from the clinical records. Initial attempts were made to contact patients telephonically. Failing which, liaison with the local tracing team was undertaken to trace patients using listed addresses. Adherence to standard practise for LTFU tracing was ensured with only the clinical staff of the facility, the contact tracing team and members of the research team who were tasked with locating LTFU patients having access to the patient identity and contact information. Reports submitted contained anonymised data. From a total of 268 patients identified with the TB outcome of LTFU on the ETR.net and EDR.web (electronic TB registers), we were only able to retrieve 71 case files. Sixty-one (61) of these case files contained invalid contact details and we were thus only able to contact 10 patients for interviews. One patient was unable to be interviewed as he had relocated to another province and two had died. The remaining seven patients identified for interviews were approached either face-to-face or telephonically. Five patients chose to be interviewed at their homes and two chose the facility. (Annexure 4). Patients who commuted to the facility for the interview were reimbursed R150 (\$10 US) in lieu of travelling expenses. Inadequate collection of patient contact information and treatment records impacts on tracing and management of patients. Sinai et al. demonstrated that it is commonplace for patients to move between facilities once they have commenced their TB treatment [33]. Often these movements occur without prior notice to the provider and rendering patient tracking difficult to trace $[3,34,35]$. Sinai et al. additionally reflected on the data quality issues within the patients' records, TB screening registers and case registers and with routine laboratory data including incompleteness, errors and discrepancies [33].

Clinical managers at each facility in collaboration with the research team identified clinicians that could be interviewed. Clinicians were currently employed at the selected health facilities; and were part of the nursing staff or doctors that were directly involved in TB care and management. Clinicians were approached face-toface for participation and interviews were arranged at their convenience. Interviews were conducted in private areas within the facility.

\section{Data analysis}

Recorded interviews were transcribed verbatim and translated to English where applicable by research 
assistants. Transcripts were checked for accuracy by the research assistants. The transcripts were further checked, and identifiers removed by two investigators with medical and doctorate level qualifications. Manual coding was used for data analysis. To validate the findings, independent coding and theme identification was conducted by the same investigators. A codebook was developed that comprised a priori codes derived from the original question guide. Emerging thematic codes were developed during the thematic analysis and added to the codebook as required. Concepts from different interviews were pooled together and integrated into common themes. For reliability, four additional investigators reviewed the codebook before themes were finalised using the deductive/inductive thematic approach. The themes are represented as direct quotes. The themes were summarised by the authors as they were developed during the analysis and the direct quotes by the participants were used to support the summary.

\section{Ethics}

Ethics approval for this study was obtained through the Human Research Ethics Committee (University of the Witwatersrand) [Ethics approval no: 170606] and the Free State Department of Health [Ethics approval no. FS_2017RP10_005]. Written consent was obtained from all participants. The interview scripts were coded, and personal identifying details were not collected.

\section{Results}

Baseline characteristics of patients interviewed showed a male predominance $(86 \%)$ with mean age of patients being 37 years (7.8 standard deviations [SD]). Patients travelled on average $9.8 \mathrm{~km}$ to the attending facility (Table 1). A total of 15 clinicians with varying experience (two Medical Doctors, one Operations Manager, nine Professional Nurses and three Enrolled Nurses), were recruited for in-depth interviews. The average duration of employment for the clinicians was 17 years (2.7 SD).

\section{Main theme 1: Patient level perspectives regarding adherence to TB treatment}

Most patients reported that they were given TB information by clinicians during their clinical visits. However, it appears that the information received by patients did not translate into improved TB clinical outcomes as evidenced by the inability of this cohort of patients to complete their TB treatment regimen. Often patients demonstrated an understanding of the disease but the social determinants of health at play within the community, such as diminished educational and employment prospects, had far reaching consequences that included TB treatment LTFU, fear of disclosure and stigmatization. Patients felt that the TB messaging received was inadequate. The sub-themes derived from the interviews drew attention to the impact of health literacy on $\mathrm{TB}$ treatment outcomes and suggested that the rigid implementation of the current $\mathrm{TB}$ treatment guidelines stifled active patient involvement in their ongoing treatment. Commonly reported reasons for LTFU in the literature (including long queues, financial difficulty attending clinic and unreliable transport) were inconsistently reported in this study and were not considered for the analysis.

\section{Subtheme 1.1: Gaps in health literacy related to information on TB treatment adherence}

Most patients demonstrated adequate knowledge of the TB screening procedures and TB symptoms. However, patients did not seem to understand the TB treatment process and importance of their roles and responsibilities in achieving successful TB outcomes. Most patients described the TB messaging received as focussed on the importance of adhering to TB treatment for the 'entire duration of therapy', despite potential side effects of the TB medication. "Yes, they tell you that you have the TB illness and tell you that if you take your treatment correctly, comply to your treatment you will be fine. They make you feel good that you end up accepting the fact that you really have TB" (\#4). Patients did not seem sufficiently prepared regarding the side effects that were experienced while on TB treatment. "Yes, they (referring to clinicians) did explain to me but though they have explained something, when it happens to you it is not the same as talking about it, when it is happening, it is you who feels the side effects of the treatment so even when they mention that, they do explain but when you experience it somewhere, that does not sit well." (\#5).

Importantly, patients seemed to lack knowledge on the length of treatment, nor that the treatment would have to be continued significantly past the point where the patient felt a subjective improvement in health. One patient described his experience as follows: "She (referring to clinician) did not tell me, she never told me [to stop] but I decided to stop the treatment. She told me that I will be finishing taking treatment on the $12^{\text {th }}$, they said I should give another sputum to check if TB is still active or what. When I went to the clinic, I produced sputum and I was okay. I was okay, my body weight was back, and it's when she told me that you will be completing your treatment" (\#7).

\section{Subtheme 1.2: Challenge to individual TB treatment plans}

Some patient's decision to discontinue treatment was in response to unmet expectations from clinicians. One patient felt that the rigidity of clinicians in failing to restructure the management plan to accommodate their requests resulted in them interrupting their treatment. "I 
was treated well but they could not when I explained to them that I will go away for work for this long (one month) and I am asking for treatment that can last for the time I am away. They could not give me like that, the way I was asking them, that is the only reason that made me to end up defaulting now" (\#5).

Some patients also felt that the clinicians were not listening to their concerns and expected them to adjust to the TB medication. "I vomited when I took the pills for the first time and I had a bit of diarrhoea. To overcome these, I went back to the clinic and they gave me soft porridge powder and told me that I will get used to the pills and they will get used to my system or body" (\#4).

Patients also felt that some of the existing systems at the public health facility were not conducive to them accessing TB treatment efficiently. "I am delayed sometimes, I go at five o'clock in the morning and come home at six o'clock in the afternoon. They are inconveniencing us. It is just the fact that when I visited the clinic due to epilepsy, when am I supposed to go that other side [to get $T B$ treatment], they are delaying us, and I would just leave it like that" (\#1). Another perceived obstacle to patients not adhering to their TB treatment plans could be the negative attitude of clinicians towards patients. "I was not feeling okay and I was coughing while at work and I lost weight and I was taking no TB treatment up until the manager/white guy came to fetch us to come back from there. I went to take my treatment after I came home, and the nurse/sisters reprimanded me there" (\#3).

"I didn't like the way she treated me and I did not allow her and looked at me, asked why did I have this and this on my neck, we were quarrelling, both of us you see .... I did not do anything, I just left" (\#6).

\section{Sub-theme 1.3: Motivators to adhering to TB treatment}

It seems that patients could be willing to adhere to their TB treatment if they are given the opportunity to be constructively involved in their health management.

"Uh, I think what can be done in situations like mine, where it is work related. I think if they can try and do as I pleaded, they should understand our complaints and our reasons because we are asking, and we are willing to get treatment the way we are asking. I think that is the solution that can be done" (\#5).

Patients also seemed to express a need for individual centred counselling which could help them develop and manage their personal TB treatment plan. "I suffered, and I could not accept the news, but I eventually accepted because it was checked from the lab sir. I eventually accepted because I was counselled. They told me to come for my treatment that is when I believed and accepted that I do have TB" (\#4).

\section{Main theme 2: Clinician level perspectives regarding patient adherence to TB treatment}

Many clinicians felt that improving the patient's TB knowledge would reinforce adherence to treatment and thus focused on sharing information on treatment completion, side effects and infection control. However, the inability of clinicians to establish rapport with patients or to identify social support challenged TB treatment adherence by patients. Clinicians perceived this as patients not following their instructions despite what they considered lengthy TB education. Having said this, the clinicians concurred that their medical management of TB lacked the socio-economic dimension to treat a social disease of this magnitude.

"Ehm from the training side with clinicians, ehm mainly its ehm, they emphasise on ... as we also know as clinicians that emphasis is mainly on them, informing patients about taking their treatment on a daily basis and the importance and when to take treatment mainly. But training, its, it doesn't, you know the training that I have attended doesn't really emphasise on the socio-economic factors of our patient," (\#8).

The subthemes below highlight how the clinician's individual interpretation of the national TB guidelines resulted in significantly different key messages being communicated to patients, how the fragmentation of the health system leads to ongoing patient and clinician frustration; and begins to outline the importance of community support in addressing TB.

\section{Subtheme 2.1: Lack of standardisation of communication regarding $T B$ therapy}

Clinicians felt empowered from the ongoing TB module training aligned to the National TB Guidelines and this was reflected broadly in their understanding of the TB transmission dynamics and their demonstrated competency in TB care provision. However, the ability to transfer this information successfully to all TB patients was possibly lacking. "I think we still have to work hard, very hard for the patients to understand TB. They really don't understand it, so there are few that are really understanding very well but I still think we still have a lot of work to do, to teach patients more about TB" (\#19).

Some clinicians anecdotally correlated successful treatment completion with the patient's knowledge of TB, as they believed this indicated that the patients were taking their illness seriously. "If they do not know, obviously if you don't have the reason why you are doing something, 
obvious it's not going to do it mos (local South African term indicating an expression) neh but if you have knowledge that you are supposed to take your medication so that you can be better, obviously you will take the medication correctly" (\#3).

During the consultations, few clinicians discussed information on the complications of interrupting or stopping treatment; or regarding the continuation of treatment should patients transfer to other facilities. When transfer letters were negotiated, there was no indication that the clinicians reinforced the dangers of stopping or discontinuing treatment. "... we do encourage them that when you know that you are going somewhere, come and get your transfer letters so that you can get the continuation of your treatment" (\#19).

\section{Subtheme 2.2: Dealing with patient frustration and health system inadequacies}

A few clinicians felt that providing TB services at a single focal point allowed experienced staff to effectively relay information on TB transmission, therapy and adherence. This interaction would create the opportunity for patients to express their expectations of clinicians and clinicians would in turn improve patient rapport and establish a supportive, therapeutic relationship. Familiarity and consistency within the health service would reassure the patient and strengthen the trust in the care provided; potentially allowing for the disclosure of difficulties. "I am like a parent to them, you are free to them, you talk, you educate the person so that he can come back again. When he is having problems though he will not be taking treatment from you, he is able to approach you to ask" (\#12).

Some clinicians felt that the staff rotation hindered rapport with the TB patients due to short rotation periods at the TB focal point. As such, clinicians were unable to gain comprehensive insight into the patients' perspective and $\mathrm{TB}$ messaging could not be personalised to the patients need. Maintaining permanent staff at the TB focal point was described as a reason for reducing treatment interruption at their facility. "No the thing is, it is impossible, here at the clinic as we are rotating and then the patients come across a lot of faces. There are those who are dependent on that certain sister, you see ... he can't be explaining himself a lot. Is it that when the other one comes in, the patient is supposed to explain himself again and that is taking him backwards" (\#12).

The personal attitudes of staff, often perceived as harsh and condescending by the patients, may have contributed to the failure in establishing rapport with the patient. Often, the inability of the clinician to develop the patient-clinician relationship resulted in abrupt discontinuation of TB treatment without the opportunity of an intervention by the clinician.
"Unfortunately, people want to be treated by happy people, attitude. So an over worked person sometimes can you know show a bad attitude and that can, maybe he is having good intention, but the patient receives it differently and next time doesn't want to come back to the clinic, so those are some of the things that can make patients not to come" (\#19).

\section{Discussion}

This exploratory study highlighted the complex interplay of patients' beliefs, perceptions and health literacy regarding TB treatment adherence and how the perceived ineffective health service delivery colluded to hinder TB treatment completion. A prominent finding of this study were the apparent gaps in communication emanating from the patient and health service. These communication gaps undermine strengthening the patient-centred approach.

Communication experts describe effective communication as a comprehendible, two-way process naming 'participation' and 'dialogue' as key elements [36]. Patient education is reinforced with communication and social mobilization programmes that together with the broader community, are essential for improving TB cure rates and enhancing sustainability [36]. Most clinicians believed that the TB messaging they delivered was comprehensive and effective and that patients were only partially receptive to the information. There are several dimensions to this statement that should be explored.

Firstly, the clinicians have all described educating their patients. However, there appears to be evidence to the contrary regarding the quality of information given by clinicians to patients. Christian et al. explored the quality of HIV and TB health care provision in the Western Cape and its alignment to the national protocols. They cited that only $43 \%$ of cases met the minimum threshold for adequate case management and protocol deviations could be attributed to poor training and knowledge, deficiencies in monitoring and the lack of clinical governance [37]. They reported consistently poor information sharing by the staff; and the importance of returning for TB results was only discussed in a third of interactions. In this study, health promotion talks at facilities addressed generic information on TB symptoms and infection control measures, encompassing how treatment completion ensured better health and prevented resistant disease, cough hygiene practices and early TB symptom identification and side effect diagnosis and management. There was no standardised guideline from which this information was drawn, and the message varied across clinicians and facilities. Consequently, there was no objective measure of whether the patients had been adequately informed about the disease or its 
management. The overall findings from the Western Cape study suggested low effort in communicating invaluable information regarding untreated $\mathrm{TB}$ and the need for treatment and acknowledged that the poor adherence to the protocols were possibly resulting in the disappointing TB outcomes [37].

Secondly, the reception of information by patients warrants critical appraisal. In the best-case scenario, knowledge leads to understanding of taking informed action, but this does not necessarily lead to the action [38] for a multitude of reasons. Reasons ranging from access, loss of income, stigma, side effects and pill burden have long been implicated $[39,40]$. The health literacy of patients has relevance in this context where patients have interrupted treatment based on subjective improvement in health. Studies from Malawi and Zambia showed that patients advised to refrain from beer, smoking and frequent sex during their TB treatment, without proper explanation of these restrictions, were likely to reconsider their presentation for treatment $[38,41]$. Patient's preference for a treatment facility was rarely discussed during the consultation and negotiation of care was not facilitated. Thus, despite DOT supporters being on duty at some facilities, the clinicians found that tracing of LTFU patients was a futile exercise given the false addresses provided by the patients. As a result, facilities were made reliant on LTFU patients self-presenting, after not been located by treatment supporters.

Finally, the insufficiencies of the patient-clinician relationship are brought into question. Patient counselling remains a critical element in reducing LTFU [38] reducing LTFU pointing to integrated behavioural counselling and $\mathrm{TB}$ care promoting adherence to treatment protocols [41, 42]. Clinicians require knowledge of TB disease and its management and excellent communications skills to ensure quality patient education and communication [43, 44]. User-friendly and culturally appropriate resources presented in local languages are a potential approach. The use of simple, written information, enhanced by visuals cues like pictograms, have been shown to enhance comprehension and recall of information [45-47]. The use of a pictorial-based TB booklet in primary health care clinics in the Eastern Cape, South Africa was perceived as an invaluable tool in patient education [48]. Illustrated information has been shown to strengthen patient communication by the provision of accurate information that promotes adherence to guidelines and minimises guesswork [49]. Whether it is with the use of new resources or in day-to day care, clinicians need adequate training in communication, particularly when the interaction is linked to treatment adherence [50]. Emerging mHealth technologies could serve to bridge this patient-clinician communication gap and reduce LTFU [51, 52] through text messaging for example $[24,53]$. However, this strategy is reliant on the access to mobile technology and the availability of current contact details which have proved dubious in this study. Arulchelva et al. conducted similar work in India and encouraged the use of mass media, such as playing health related videos on mobile phones, in addition for personal communication [54].

Most TB patients designated LTFU cited the underlying inability to negotiate their treatment plans as the reason for the interruption in care. It appears that the needs of the clinician during the consultation, described as efficiently relaying information on TB treatment and adherence, were met. However, whether this information appropriately addressed the patients concerns and expectations appears only in the context of case-finding in the literature [55-60] and not on treatment outcomes in South Africa and globally. Similar findings from a previous study demonstrated that despite standardised guidelines effectively contributing to health coverage; ignoring the subjective biopsychosocial aspects of care particularly in rigid health systems resulted in 'dehumanising' the care process [25].

Adopting the patient centered approach is acknowledged to be directly beneficial to patients as it allows the clinician to reach an understanding of the patient's expectations, feelings and social context of the illness [61]. The clinician that assumes the role of expert but remains an equal in the relationship is likely to achieve better treatment outcomes. Discussion of management plans with the patient will allow for their preferences to be considered, discussed and incorporated; thereby adapting care to suit the individualised needs of the patient. More widely, the patient centred approach focusses on empowering TB patients and their communities, social support programmes and enhanced communication and partnership between community and health sectors [62].

\section{Strength and limitations}

An important strength of this study is the study being based in a high-density population, with a significant TB disease burden. Further, the opinions of both the patients and clinicians were sought allowing for the exploration of TB treatment adherence from differing perspectives. This study explored the reasons for discontinuing TB treatment by approaching those who had stopped TB treatment. However, the absence of the views of those who had successfully completed treatment, for the purposes of meaningful comparison, may be considered a limitation of this study. We were unable to access all the patients that were LTFU as they had moved away, provided incorrect contact details or the data was missing. Their inclusion may have yielded additional insights. Potentially, some of the responses 
obtained may have been limited given the sensitive nature of TB and its association with HIV, which also carries a significant burden of stigma and discrimination. The study was limited to a single district in the Free State Province, thus the findings cannot be extrapolated to other settings.

\section{Conclusions}

This study reiterates the need for exploring the critical socio-cultural interface between clinician and patients in order to achieve improved TB outcomes rather than the current dependence on biomedical interventions. Enhancing communication and developing innovative strategies to convey $\mathrm{TB}$ messaging to patients and the community should remain a critical focus of the clinician. Further research is warranted in developing early warning systems in identifying those at risk of treatment interruption and in developing and testing communication tools that actively promote treatment adherence. Lastly, it is vitally important to acknowledge the crucial role nurse clinicians play in TB management and control, thus ensuring they are suitably trained cannot be over-emphasized. TB remains a social disease, the successful management of which hinges on patient-centred care.

\section{Supplementary information}

Supplementary information accompanies this paper at https://doi.org/10. 1186/s12889-020-08562-3.

Additional file 1: Annexure 1. Patient Interview Guide. Annexure 2. Clinician Interview Guide. Annexure 3. Characteristics of Participants.

Annexure 4. Patient Recruitment Strategy.

\section{Abbreviations}

AIDS: Acquired immunodeficiency syndrome; DOTS: Directly observed treatment, short course; GCP: Good Clinical Practice; HIV: Human immunodeficiency virus; IDI: In-depth interviews; LTFU: Loss to follow up; PHC: Primary health care; SD: Standard deviations; TB: Tuberculosis; WHO: World Health Organization

\section{Acknowledgements}

The authors would like to thank the Management and Staff at MUCPP CHC Pelonomi Polyclinic and Pule Sefatsa CHC for their support. The authors extend their gratitude to all the patients and Clinicians who participated in this study. The authors acknowledge the excellent work from Research Assistants Mrs. K Ndamase, Mr. L Letebele, Mrs. E Lekitane in conducting the interviews. In addition, the commendable coordinating efforts of the extended research team (Data Coordinator: Mrs. B Manzini-Ali Research Assistants: Ms. L Makheta, Mrs. N Mathole, Ms. Matshuleka) in locating patients for interviews.

\section{Authors' contributions}

NM designed the study and research questions and gathered the literature. NM, AS and CCM created the interview schedule and study materials. AS managed the recruitment of participants and the conduct of interviews. NM, AS and CCM were responsible for transcription and data analysis. NM wrote the first and subsequent drafts. CCM supported data analysis and was a major contributor in writing and editing the manuscript. SC, ZN, DM and GS provided critical revision for important intellectual content. All authors have given final approval of the version to be published.

\section{Funding}

This study was funded by a grant received from the Free State Department of Health (DoH (FS) 81/2016/2017). The Department played no role in the development or implementation of the research but intends to use the findings to improve the quality of their service provision.

\section{Availability of data and materials}

The datasets used and analysed during the current study are available from the corresponding author on reasonable request.

\section{Ethics approval and consent to participate}

Ethics approval for this study was obtained through the Human Research Ethics Committee (University of the Witwatersrand) [Ethics approval no: 170606] and the Free State Department of Health [Ethics approval no. FS_2017RP10_005]. All participants were given a Participant Information Sheet when invited to the study and written consent was obtained from all participants. The interview scripts were coded, and personal identifying details were not collected.

\section{Consent for publication}

Not applicable.

\section{Competing interests}

The authors declare that they have no competing interests.

\section{Author details}

${ }^{1}$ The Aurum Institute, Johannesburg, South Africa. ${ }^{2}$ College of Medicine and Dentistry, James Cook University, 1 James Cook Drive, Douglas, Townsville, Queensland 4814, Australia. ${ }^{3}$ TB Programme, Department of Health, Bloemfontein, Free State Province, South Africa. ${ }^{4}$ School of Public Health, Faculty of Health Sciences, University of the Witwatersrand, Johannesburg, South Africa.

Received: 16 September 2019 Accepted: 20 March 2020

Published online: 06 April 2020

\section{References}

1. Global tuberculosis report 2019. Geneva: World Health Organization; 2019. Licence: CC BY-NC-SA 3.0 IGO. https://www.who.int/tb/publications/global_ report/en/. Accessed 07 Jan 2020.

2. Padayatchi N, Daftary A, Naidu N, Naidoo K, Pai M. Tuberculosis: treatment failure, or failure to treat? Lessons from India and South Africa. BMJ Glob Health. 2019;4(1):e001097.

3. Naidoo P, Theron G, Rangaka MX, Chihota VN, Vaughan L, Brey ZO, et al. The South African tuberculosis care cascade: estimated losses and methodological challenges. J Infect Dis. 2017;216(suppl_7):S702-s13.

4. Goosby E, Jamison D, Swaminathan S, Reid M, Zuccala E. The Lancet Commission on tuberculosis: building a tuberculosis-free world. Lancet (London, England). 2018;391(10126):1132-3.

5. Treatment of Tuberculosis: Guidelines. 4th edition. Geneva: World Health Organization; 2010. 6, Supervision and patient support. https://www.ncbi. nlm.nih.gov/books/NBK138737/. Accessed 07 Jan 2020

6. Foster N, Vassall A, Cleary S, Cunnama L, Churchyard G, Sinanovic E. The economic burden of TB diagnosis and treatment in South Africa. Soc SC Med (1982). 2015;130:42-50.

7. Collins D, Njuguna C. The economic cost of non-adherence to TB medicines resulting from stock-outs and loss to follow-up in Kenya. In: Submitted to the US Agency for international development by the Systems for Improved Access to pharmaceuticals and services (SIAPS) program. Arlington: Management Sciences for Health; 2016. https://www.msh.org/sites/default/ files/17-029_siaps_kenya_report.pdf. Accessed 05 Jan 2020

8. Gandy M, Zumla A. The resurgence of disease: social and historical perspectives on the 'new' tuberculosis. Soc Sci Med. 2002;55(3):385-96 discussion 97-401

9. Tola HH, Tol A, Shojaeizadeh D, Garmaroudi G. Tuberculosis treatment nonadherence and lost to follow up among TB patients with or without HIV in developing countries: a systematic review. Iran J Public Health. 2015:44(1):111.

10. Cherkaoui I, Sabouni R, Ghali I, Kizub D, Billioux AC, Bennani K, et al. Treatment default amongst patients with tuberculosis in urban Morocco: 
predicting and explaining default and post-default sputum smear and drug susceptibility results. PLoS One. 2014;9(4):e93574

11. Wohlleben J, Makhmudova M, Saidova F, Azamova S, Mergenthaler C, Verver S. Risk factors associated with loss to follow-up from tuberculosis treatment in Tajikistan: a case-control study. BMC Infect Dis. 2017;17(1):543.

12. Sanchez-Padilla E, Marquer C, Kalon S, Qayyum S, Hayrapetyan A, Varaine F, et al. Reasons for defaulting from drug-resistant tuberculosis treatment in Armenia: a quantitative and qualitative study. Int J Tuberc Lung Dis. 2014; 18(2):160-7.

13. Roy N, Basu M, Das S, Mandal A, Dutt D, Dasgupta S. Risk factors associated with default among tuberculosis patients in Darjeeling district of West Bengal, India. J Fam Med Prim Care. 2015;4(3):388-94.

14. Muture BN, Keraka MN, Kimuu PK, Kabiru EW, Ombeka VO, Oguya F. Factors associated with default from treatment among tuberculosis patients in Nairobi province, Kenya: a case control study. BMC Public Health. 2011;11:696.

15. Kigozi G, Heunis C, Chikobvu P, Botha S, van Rensburg D. Factors influencing treatment default among tuberculosis patients in a high burden province of South Africa. Int J Infect Dis. 2017;54:95-102.

16. Ershova JV, Podewils L, Bronner LE, Stockwell HG, Dlamini SS, Mametja LD. Evaluation of adherence to national treatment guidelines among tuberculosis patients in three provinces of South Africa. S Afr Med J. 2014; 104(5):362-8.

17. Finlay A, Lancaster J, Holtz TH, Weyer K, Miranda A, van der Walt M. Patientand provider-level risk factors associated with default from tuberculosis treatment, South Africa, 2002: a case-control study. BMC Public Health. 2012; $12: 56$.

18. Bristow CC, Podewils $L$, Bronner LE, Bantubani N, Walt M, Peters A, et al. TB tracer teams in South Africa: knowledge, practices and challenges of tracing TB patients to improve adherence. BMC Public Health. 2013;13:801.

19. Bronner LE, Podewils $L$, Peters $A$, Somnath $P$, Nshuti $L$, van der Walt $M$, et al. Impact of community tracer teams on treatment outcomes among tuberculosis patients in South Africa. BMC Public Health. 2012;12:621.

20. Daftary A, Padayatchi N. Provider perspectives on drug-resistant tuberculosis and human immunodeficiency virus care in South Africa: a qualitative case study. Int J Tuberc Lung Dis. 2016;20(11):1483-8.

21. Gugssa Boru C, Shimels T, Bilal Al. Factors contributing to non-adherence with treatment among TB patients in Sodo Woreda, Gurage zone, southern Ethiopia: a qualitative study. J Infect Public Health. 2017;10(5):527-33.

22. Straetemans M, Bakker MI, Mitchell EMH. Correlates of observing and willingness to report stigma towards HIV clients by (TB) health workers in Africa. Int J Tuberc Lung Dis. 2017;21(11):6-18.

23. Gebreweld FH, Kifle MM, Gebremicheal FE, Simel LL, Gezae MM, Ghebreyesus SS, et al. Factors influencing adherence to tuberculosis treatment in Asmara, Eritrea: a qualitative study. J Health Popul Nutr. 2018; 37(1):1.

24. Ali SM, Naureen F, Noor A, Fatima I, Viney K, Ishaq M, et al. Loss-to-followup and delay to treatment initiation in Pakistan's national tuberculosis control programme. BMC Public Health. 2018;18(1):335.

25. De Man J, Mayega RW, Sarkar N, Waweru E, Leys M, Van Olmen J, et al. Patient-centered care and people-centered health systems in Sub-Saharan Africa: Why so little of something so badly needed? Int J Person Centred Med. 2016;6(3):12.

26. Reid MJA, Arinaminpathy N, Bloom A, Bloom BR, Boehme C, Chaisson R, et al. Building a tuberculosis-free world: The Lancet Commission on tuberculosis. Lancet (London, England). 2019;393(10178):1331-84.

27. Zuccala E, Horton R. Time to bring tuberculosis out of the shadows. Lancet (London, England). 2019;393(10178):1267-8.

28. Steyn M, van der Merwe N, Dick J, Borcherds R, Wilding RJ. Communication with TB patients; a neglected dimension of effective treatment? Curationis. 1997;20(1):53-6.

29. McGirr J, Seal A, Barnard A, Cheek C, Garne D, Greenhill J, et al. The Australian rural clinical school (RCS) program supports rural medical workforce: evidence from a cross-sectional study of 12 RCSs. Rural Remote Health. 2019;19(1):4971.

30. Day C, Gray A, Ndlovu N. Health and related indicators 2018. In: Rispel LC, Padarath A, editors. South African health review 2018. Durban: Health Systems Trust; 2018. http://www.hst.org.za/publications/Pages/SAHR2018. Accessed 05 Jan 2020.

31. Maluleke R. Mortality and causes of death in South Africa, 2016: Findings from death notification. Pretoria: Statistics South Africa; 2018. https://www. statssa.gov.za/publications/P03093/P030932016.pdf. Accessed 05 Jan 2020.
32. Cristobal F, Worley P. Can medical education in poor rural areas be costeffective and sustainable: the case of the Ateneo de Zamboanga University School of Medicine. Rural Remote Health. 2012;12:1835.

33. Sinai I, Cleghorn F, Kinkel HF. Improving management of tuberculosis in people living with HIV in South Africa through integration of HIV and tuberculosis services: a proof of concept study. BMC Health Serv Res. 2018; 18(1):711.

34. Nglazi MD, Kaplan R, Orrell C, Myer L, Wood R, Bekker LG, et al. Increasing transfers-out from an antiretroviral treatment service in South Africa: patient characteristics and rates of virological non-suppression. PLoS One. 2013;8(3): e57907.

35. Skinner D, Claassens M. It's complicated: why do tuberculosis patients not initiate or stay adherent to treatment? A qualitative study from South Africa. BMC Infect Dis. 2016;16(1):712.

36. Cristobal F, Worley P, et al. Lancet (London, England). 2011;377(9773):1235-6 author reply 8-9.

37. Christian CS, Gerdtham UG, Hompashe D, Smith A, Burger R. Measuring quality gaps in TB dcreening in South Africa using standardised patient analysis. Int J Environ Res Public Health. 2018;15(4). https://doi.org/10.3390/ ijerph15040729.

38. Nyasulu P, Sikwese $S$, Chirwa $T$, Makanjee $C$, Mmanga M, Babalola JO, et al. Knowledge, beliefs, and perceptions of tuberculosis among community members in Ntcheu district, Malawi. J Multidiscip Healthc. 2018;11:375-89

39. Gebremariam MK, Bjune GA, Frich JC. Barriers and facilitators of adherence to TB treatment in patients on concomitant TB and HIV treatment: a qualitative study. BMC Public Health. 2010;10:651.

40. Sagbakken M, Frich JC, Bjune G. Barriers and enablers in the management of tuberculosis treatment in Addis Ababa, Ethiopia: a qualitative study. BMC Public Health. 2008:8:11.

41. Bond $V$, Nyblade L. The importance of addressing the unfolding TB-HIV stigma in high HIV prevalence settings. J Community Appl Soc Psychol. 2006;16(6):452-61

42. Wolfgang R, Wakely L, Smith T, Burrows J, Little A, Brown LJ. Immersive placement experiences promote rural intent in allied health students of urban and rural origin. J Multidiscip Healthc. 2019;12:699-710.

43. Ibrahim LM, Hadjia IS, Nguku P, Waziri NE, Akhimien MO, Patrobas P, et al. Health care workers' knowledge and attitude towards TB patients under Direct Observation of Treatment in Plateau state Nigeria, 2011. Pan Afr Med J. 2014;18(Suppl 1):8.

44. Chimbindi N, Barnighausen T, Newell ML. Patient satisfaction with HIV and TB treatment in a public programme in rural KwaZulu-Natal: evidence from patient-exit interviews. BMC Health Serv Res. 2014;14:32.

45. Houts PS, Doak CC, Doak LG, Loscalzo MJ. The role of pictures in improving health communication: a review of research on attention, comprehension, recall, and adherence. Patient Educ Couns. 2006;61(2):173-90.

46. Dowse R, Ehlers MS. The evaluation of pharmaceutical pictograms in a lowliterate south African population. Patient Educ Couns. 2001;45(2):87-99.

47. Kenny T, Wilson RG, Purves IN, Clark J Sr, Newton LD, Newton DP, et al. A PIL for every ill? Patient information leaflets (PILs): a review of past, present and future use. Fam Pract. 1998;15(5):471-9.

48. Okeyo ILA, Dowse R. An illustrated booklet for reinforcing community health worker knowledge of tuberculosis and facilitating patient counselling. Afr J Prim Health Care Fam Med. 2018;10(1):e1-7.

49. Jennings L, Yebadokpo AS, Affo J, Agbogbe M, Tankoano A. Task shifting in maternal and newborn care: a non-inferiority study examining delegation of antenatal counseling to lay nurse aides supported by job aids in Benin. Implement Sci. 2011;6:2.

50. Mishra P, Hansen EH, Sabroe S, Kafle KK. Adherence is associated with the quality of professional-patient interaction in directly observed treatment short-course, DOTS. Patient Educ Couns. 2006;63(1-2):29-37.

51. Hirsch-Moverman Y, Daftary A, Yuengling KA, Saito S, Ntoane M, Frederix K, et al. Using mHealth for HIV/TB treatment support in Lesotho: enhancing patient-provider communication in the START study. J Acquir Immune Defic Syndr. 2017;74(Suppl 1):S37-s43.

52. Elangovan R, Arulchelvan S. A study on the role of Mobile phone communication in tuberculosis DOTS treatment. Indian J Community Med. 2013;38(4):229-33.

53. John HVG, Yan J, Hoffman SJ. A WHO report: framework for action on Interprofessional education and collaborative practice. J Allied Health. 2010; 39(3):196. 
54. Arulchelvan S, Elangovan R. Effective communication approaches in tuberculosis control: health workers' perceptions and experiences. Indian J Tuberc. 2017;64(4):318-22.

55. Marimwe C, Dowse R. Health literacy test for limited literacy populations (HELT-LL): validation in South Africa. Cogent Med. 2019;6(1):1650417.

56. De Schacht C, Mutaquiha C, Faria F, Castro G, Manaca N, Manhiça I, et al. Barriers to access and adherence to tuberculosis services, as perceived by patients: a qualitative study in Mozambique. PLoS One. 2019;14(7):e0219470.

57. Nautiyal RG, Mittal S, Awasthi S, Singh RK. Knowledge about tuberculosis among pulmonary tuberculosis patients: a cross-sectional study from Uttarakhand. J Fam Med Prim Care. 2019;8(5):1735-40.

58. Penaloza R, Navarro Jl, Jolly PE, Junkins A, Seas C, Otero L. Health literacy and knowledge related to tuberculosis among outpatients at a referral hospital in Lima, Peru. Res Rep Trop Med. 2019;10:1-10.

59. Kigozi NG, Heunis JC, Engelbrecht MC, Janse van Rensburg AP, van Rensburg HCJD. Tuberculosis knowledge, attitudes and practices of patients at primary health care facilities in a South African metropolitan: research towards improved health education. BMC Public Health. 2017;17(1):795.

60. Muniyandi M, Rao VG, Bhat J, Yadav R, Sharma RK, Bhondeley MK. Health literacy on tuberculosis amongst vulnerable segment of population: special reference to Saharia tribe in Central India. Indian J Med Res. 2015;141(5): 640-7.

61. McWhinney IR. Patient-centred and doctor-centred models of clinical decision-making. In: Sheldon M, Brooke J, Rector A, editors. Decision-making in general practice. London: Macmillan Education UK; 1985. p. 31-46.

62. Berhe G, Enquselassie F, Aseffa A. Treatment outcome of smear-positive pulmonary tuberculosis patients in Tigray Region, Northern Ethiopia. BMC Public Health. 2012;12:537.

\section{Publisher's Note}

Springer Nature remains neutral with regard to jurisdictional claims in published maps and institutional affiliations.

Ready to submit your research? Choose BMC and benefit from:

- fast, convenient online submission

- thorough peer review by experienced researchers in your field

- rapid publication on acceptance

- support for research data, including large and complex data types

- gold Open Access which fosters wider collaboration and increased citations

- maximum visibility for your research: over $100 \mathrm{M}$ website views per year

At $\mathrm{BMC}$, research is always in progress.

Learn more biomedcentral.com/submissions 